\title{
Lactogenic studies of Stachytarphetajamaicensis Linn. (Vahl) family (Verbenaceae)leaves on serum prolactin level of lactatingalbino rats.
}

\author{
Odoh, U. E., Udodeme, H. O*, Ugwu, N. P., Diovu, E. O and Ezugwu C.O. \\ (Department of Pharmacognosy and Environmental Medicine, Faculty of Pharmaceutical Sciences, University \\ of Nigeria,Nsukka.)
}

\begin{abstract}
Theeffect of crude methanol extract (CME) and fractions (n-hexane, ethyl acetate, $n$-butanol and water) of Stachytarphetajamaicensis (SJ) leaves were evaluated on serum prolactin (PRL) secretionin albino rats. Female rats that received oral doses $(200,400$ or $800 \mathrm{mg} / \mathrm{kg})$ of CME during their first lactation showed a dose-dependent significant increase $(P<0.05)$ in the serum prolactin level when compared to control group. However, the ethyl acetate fraction in the fraction-treated rats during their first lactation exhibited the highest activity when compared to the control with potency greatly higher than the standard drug metoclopramide. The order of activity of the fractions is: $E F>B F>H F>W F(800 \mathrm{mg} / \mathrm{kg})$ respectively. The estrogen-primed treated rats produced a high serum $P R L$ concentration compared to the non-primed rats.In addition, mammary gland of estrogen-primed rats treated with the CME and fractions showedclear lobulo-alveolar development with milk secretion. The acute toxicity test of CME and fractions of SJ indicated that the plant is safe as the $L D_{50}$ was found to be above $5000 \mathrm{mg} / \mathrm{kg}$. This study demonstrates that SJ leaves can stimulate PRL secretion in the female rats which supports its traditional usage in lactating women.
\end{abstract}

Keywords:Lactation, mammary gland, pituitary, prolactin, Stachytarphetajamaicensis.

\section{Introduction}

The onset of copious milk secretion at parturition is a feature of lactation in all placental mammalsto meet the nutritional requirement of relatively well-developed neonates. African women with insufficient milk production locally use plant extracts to induce milk supply since breast-feeding is important and highly encouraged for the survival of the newborn [1]. SJ is a plant of the family Verbenaceae. It originates from the New World Tropics and at present has a pantropical distribution [2]. It is now a pantropical weed present in East and West Africa, Madagascar, the Ryukyu Islands of Japan, Taiwan, the Indian Subcontinent, Australia, Indonesia, Malaysia and on many pacific Islands [3]. SJ is commonly known as Blue porterweed and locally known in Hausa as TsarkiyarKuиsuu, in Yoruba as Agogolgun and in Efik as Aran-umon. The family has about 100 genera and 3,000 species distributed mostly in the tropical and subtropical regions. It is a perennial herbaceous or semi-woody shrub with dull dark green leaves often covered with powder which gives it a bluish shine.

In African ethnomedicinal practices, most plant extracts are generally used in the form of infusion or decoction. SJ is used in ethnomedicine to treat numerous ailments. So, plant materials which have been found to be effective as a galactogogue are used as medicines in traditional, and some aspects of convectional healthcare practices. Traditionally, the root decoctions are abortive [4]. In phytomedicine, the leaves of SJ are used for birth control, abortion, treatment of menstrual disorders and as a galactogogue [5]. Decoctions of leaves are vermifuge to children [4]. Triturated fresh leaves have been used on ulcers. It is also used as maturative cataplasm for boils. Bruised leaves have been rubbed on sprains and bruises [3]. In Brazil, it is used for cough, fever, to expel worms and promote menstruation; as a diuretic and laxative. It is also used for rheumatism [4]. A flavonoid, scuttelarain has been isolated, with cardioprotective, anti-inflammatory and antiviral actions [4]. Hopidulin, another flavonioids, is reported to be bronchodilator, antispasmodic and anti-asthmatic [4]. Study of leaves isolated a new lanostanetriterpenoid $16 \beta$-( $\beta$-D-glycopyramosyl-3-8, dihydroxylanstan-5,22-diene-11methroxy-1 $\beta$-yl-6-0-(2,3-dimethoxybenzoyl)- $\beta$-dglycopyranoside [5]. The methanol extract of the leaves of the plant showed significant antidiarrheal activity and moderate inhibitory activity against E.coli, Staph. epidermis and P. aeruginosa [6]. Crude aqueous extract showed activity against B. subtilis, E. coli, C. albicans, S. aureus, P. aeruginosa, P. valgaris, and P. mirabilis. [7]. Study showed more antimicrobial activity with the chloroform extract against gram positive organisms like S. aureus, E. faecalis, and B. subtilis. The chloroform and alcohol extracts showed antifungal activity against C. albicans and Saccharomyces cereviseae [8].Inhibitory effect of leaf extracts of the plant was done on the respiratory burst of rat macrophages. Extract showed potent $\mathrm{O}_{2^{-}}$ scavening activity. Study suggests SJ may have potential pharmaceutical value for immunologic disease related to oxidative stress [9]. The ethanol extract of SJ exhibited significant schizonticidal activity comparable to that 
of the standard drug, chloroquine. The antiplasmodial activity confirms its folkloric use in the treatment of malaria [10]. The effects of SJ tea on plasma lipid profile and atherogenic indices were studied in rabbits. Treatment caused significant decrease in plasma total cholesterol, LDL, VLDL and triglycerides with also significant decrease in atherogenic indices. The result suggests the use of SJ tea in the management of primary and secondary dyslipidemia [11]. Study evaluated the analgesic activity of various extract of dried leaves on acetic induced writing responses in Swiss albino mice. Result showed significant analgesic effect [12]. Study evaluated the wound healing effect of ahydroalcoholic leaf extract of SJ on streptozotocin induced diabetic rats. Results showed significant dose-dependent wound healing potential with a significant increase in percentage wound closure, tensile strength, hydroxyproline, Hexosamine, DNA and total protein content together with decrease in period of epithelization and blood sugar levels [13].Some plants such as Trigonellafoecumgraecum, Galegaofficinalis, Silybummarianum, Cnicusbenedictus have been used in many cultures to stimulate milk production in women and in dairy animals [14].

Most of the galactogogues have not been scientifically evaluated but traditional use suggests their safety and some efficacy. PRL and Oxytocin are indeed the hormones that are essential for the initiation and maintenance of lactation which are regulated by an intact hypothalamic pituitary axis of the brain [15].Based on the ethnomedicinal use and belief that SJ can increase milk supply in lactating women, experiments were carried out to determine the effect of the crude methanol extract and fractions of SJ leaves on serum PRL secretion and mammary gland development in rats.

\subsection{Chemicals and Reagents}

\section{Materials and Methods}

Accu-BindElisa Microwells (Monobind Inc. Lake forest, CA 92630, USA) a Prolactin Hormone (PRL) Test System, Metoclopramide (NAFDAC Reg. No. 04-5946) was used as the standard drug; Estradiol Valerate USP (Cadila Healthcare Ltd, Ponda) was used to stimulate pregnancy in the virgin rats. All chemicals, solvents and reagents were of analytical grade. Methanol (JHD), n-hexane (JHD), ethylacetate (JHD), n-butanol (JHD) and Water were used for extraction and fractionation. Distilled water, $30 \%$ Tween 80 and Sesame oil were used for pharmacological studies.

\subsection{Collection and Preparation of Plant materials}

The samples of SJ leaves were collected in Udenu Local Government in Enugu State of Nigeria in June, 2014. The plant was identified and authenticated by Mr. A.O. Ozioko, a taxonomist of the International Centre for Ethnomedicine and Drug Development (Inter CEDD) and a voucher specimen (Intercedd/16015) was deposited in the Herbarium section of Inter CEDD, 110 Aku Road Nsukka, Nigeria.

Traditionally, a nursing mother $( \pm 60 \mathrm{~kg}$ ) drinks an extract of about $60 \mathrm{~g}$ dry SJ leaves per liter per day. For this experiment, SJ fresh leaves were air-dried in shade, pulverized and the leaf powder was used for extraction and further experimental studies. Extraction and fractionation were conducted in the Department of Pharmacognosy and Environmental Medicine, Faculty of Pharmaceutical Sciences, University of Nigeria, Nsukka. Extraction was done using maceration method while the crude methanol extract were successively fractionated by using n-Hexane, Ethyl acetate and n-Butanol reagents. The filtrate from the CME and fractions were concentrated in a rotary vacuum evaporatorat a controlled temperature of $40-45^{\circ} \mathrm{C}$ while the water fraction (WF) remaining after the fractionation process was evaporated using freeze dryer. The extract and fractions obtained were transferred into a sterile sample container and preserved in a refrigerator.

\subsection{Animals}

The study was compiled with the ethical committee guidelines of University of Nigeria Veterinary Teaching Hospital, Nsukka and the procedures followed were in accord with the ethical standards of University of Nigeria, Nsukka, Nigeria. Adult female Swiss albino rats (weighing 120-160 g) and mice (weighing 24-36 g) of either sex were obtained from Zoological Garden of the Department of Zoology, University of Nigeria, Nsukka. The albino rats were housed and mated with the male rats in stainless steel metal cages with wood chips on the floor under standard laboratory condition with $12 \mathrm{~h}$ dark/light cycle. They were fed with commercial feeds and tap water ad libitum. Following birth, the litters'were culled to 7 litters per dam.

\subsection{Phytochemical Analysis}

Preliminary qualitative chemical tests were carried out using standard methods $[16,17,18]$. Crude extracts and fractions were screened for the presence of chemical constituents.

\subsection{Acute-toxicity Studies}

The lethal dose $\left(\mathrm{LD}_{50}\right)$ of the plant extract was determined by the method of Lorke [19] using 13 rats. In the first phase, rats were divided into 3 groups of 3 rats each and treated with the CME of leaves at dosesof 
10,100 and $1000 \mathrm{mg} / \mathrm{kg}$ body weight (orally). They were observed for $24 \mathrm{hr}$ for signs of toxicity. In the second phase, 4 rats were divided into 4 groups of 1 rat each and also treated with the CME of the plant leaves at doses of 1000, 1600, 2900 and $5000 \mathrm{mg} / \mathrm{kg}$ body weight (orally).

The median lethal dose $\left(\mathrm{LD}_{50}\right)$ was calculated using the second phase. The whole processes were also carried out for the fractions of the plant to determine their lethal doses.

\subsection{Experimental Protocols}

\subsubsection{Effect of Oral Treatment of SJ Crude Methanol Extract on Serum PRL Concentration}

Twenty-five (25) lactating dams weighing 180-250 $\mathrm{g}$ at the beginning of lactation and suckling seven pups were used for this experiment. They were divided into five experimental groups of five lactating rats in each group $(\mathrm{n}=5)$. Group I served as normal control and received distilled water $(5 \mathrm{ml})$, Group II received the standard drug metoclopramide (5 mg/kg) [20] and Groups III - V received (200, 400 and $800 \mathrm{mg} / \mathrm{kg}$ body weight) of the extract respectively. All animals were treated daily and all groups received the extract and the drug for six days starting from day 4-9 of lactation [21]. All administrations were done orally with a gavage syringe. On day 10 of the experiment, fasting morning blood samples were collected from the periorbital of the eye using a plain redtop capillary tube without anticoagulant. The blood was allowed to clot and the specimens were centrifuged. The serum obtained was assayed for PRL content using Prolactin kit [22]. All the animals were then euthanized and disposed properly.

\subsubsection{Effect of Oral Treatment of SJ Fractions on Serum PRL Concentration}

Thirty (30) lactating dams weighing 140-250 $\mathrm{g}$ at the beginning of lactation and suckling seven pups were randomly selected and used for this experiment. The animals were divided into six experimental groups of five lactating rats in each group $(\mathrm{n}=5)$. Group I was treated orally with $5 \mathrm{ml}$ of distilled water (normal control) while Group II received 5mg/kg metoclopramide [20] (standard drug). Groups III - VI received ethyl acetate, nhexane, n-butanol and water $(800 \mathrm{mg} / \mathrm{kg}) \mathrm{BW}$ of fractions respectively. All animals were treated daily and all groups received the fractions of SJ and the drug (metoclopramide) for six days starting from day 4-9of lactation [21]. All administrations were done orally with a gavage syringe. On day 10 of the experiment, fasting morning blood samples were collected as previously described and the serum obtained was assayed for PRL content using Prolactin kit [22]. All the animals were then euthanized and disposed properly.

\subsubsection{Effect of Oral Treatment of SJ Crude Extract on Mammary Gland Tissues}

Forty (40) virgin female rats aged 60-90 days were divided into 2 groups. The first group first received a subcutaneous injection of estradiol $\left(E_{2}\right)$ in a dose of $10 \mu \mathrm{g} / 0.1 \mathrm{ml}$ sesame oil twice daily for 2 days. Subsequently, they were divided into 4 subgroups and received an oral administration of either $5 \mathrm{ml}$ distilled water or $200 \mathrm{mg}$ or $400 \mathrm{mg}$ or $800 \mathrm{mg} \mathrm{SJ}$ extract $/ \mathrm{kg} \mathrm{BW}$ of twice daily for 5 days. The second group first received an oral administration of $5 \mathrm{ml}$ of distilled water and was then divided into 4 subgroups receiving the same oral administration of the extract as the first group. On the $6^{\text {th }}$ day, serum PRL was obtained for PRL content as previously described. All animals were euthanizedand the two inguinal mammary glands were harvested. They were immediately fixed in $10 \%$ formal-saline and embedded in paraffin after dehydration in a graded series of ethanol and xylene. Paraffin sections $(5 \mu \mathrm{m})$ of the mammary glands were sliced and stained with Harris hematoxilin and eosin [23]. Mammary gland structures were identified according to Russo and Russo [24] and Masso-Welch [25] using a microscope coupled to an image analysis system.

\subsubsection{Effect of Oral Treatment of SJ Fractions on Mammary Gland Tissue}

Fifty (50) virgin female rats aged 60 - 90 days were divided into 2 groups. The first group first received a subcutaneous injection of estradiol $\left(E_{2}\right)$ in a dose of $10 \mu \mathrm{g} / 0.1 \mathrm{ml}$ sesame oil twice daily for 2 days. Subsequently they were divided into 5 subgroups and received an oral administration of either $5 \mathrm{ml}$ distilled water or ethyl acetate, n-hexane, n-butanol and water $(800 \mathrm{mg} / \mathrm{kg})$ body weight of fractions respectively twice daily for 5 days. The second group first received an oral administration of $5 \mathrm{ml}$ distilled water and was then divided into 5 subgroups receiving the same oral administration of the fractions as the first group. On the $6^{\text {th }}$ day, serum PRL was also obtained for PRL content as previously described. All animals were euthanized and the two inguinal mammary glands were harvested. The processes of fixation, dehydration, embedding, staining and identification of the mammary glands were carried out as previously described.

\subsection{Statistical Analysis}

Data obtained were analyzed using one-way analysis of variance (ANOVA). Differences between means were accepted significant at $\mathrm{P}<0.05$. Results were presented as mean \pm standard error of mean(Mean \pm SEM). 


\subsection{Percentage Yield}

\section{Results}

The extraction process yielded the Crude Methanol Extract (CME) while the fractionation process yielded the n-hexane, ethyl acetate, n-butanol and water fractions with their respective percentage yields as shown in TABLE 1.

Table 1: Result of percentage (\%) yield of the extraction and fractionation processes

\begin{tabular}{|l|l|l|l|}
\hline Sample & Quantity $(\mathrm{g})$ & Yield $(\mathrm{g})$ & $\%$ Yield \\
\hline Crude Extraction & 1890.00 & 395.00 & 19.31 \\
\hline N-Hexane fraction & 395.00 & 71.40 & 35.70 \\
\hline Ethyl acetate fraction & 395.00 & 19.18 & 9.59 \\
\hline N-Butanol fraction & 395.00 & 50.31 & 25.16 \\
\hline Water fraction & 395.00 & 54.50 & 27.29 \\
\hline
\end{tabular}

\subsection{Phytochemical analysis}

The preliminary phytochemical analysis showed the presence of phytochemicals in both crude methanol extract and fractions as shown in TABLE 2.

Table 2: Results of phytochemical analysis

\begin{tabular}{|c|c|c|c|c|c|c|}
\hline \multirow[t]{2}{*}{$\mathrm{S} / \mathrm{N}$} & \multirow[t]{2}{*}{ Constituents } & \multicolumn{5}{|c|}{ Inference } \\
\hline & & CME & $\mathrm{HF}$ & $\mathrm{EF}$ & $\mathrm{BF}$ & WF \\
\hline & Carbohydrates & + & - & - & + & + \\
\hline & Reducing sugars & + & - & - & + & + \\
\hline & Alkaloids & + & + & + & + & + \\
\hline & Glycosides & + & - & + & + & + \\
\hline & Saponins & + & - & + & + & + \\
\hline & Tannins & + & - & + & + & + \\
\hline & Flavonoids & + & - & + & + & - \\
\hline & Resins & + & + & + & - & - \\
\hline & Proteins & + & - & + & + & + \\
\hline & Oils & + & + & - & - & - \\
\hline & Steroids & + & + & + & + & + \\
\hline & Terpenoids & + & + & - & - & - \\
\hline
\end{tabular}

Key: $\mathrm{CME}=$ Crude Methanol extract, $\mathrm{HF}=\mathrm{N}-\mathrm{Hexane}$ fraction, $\mathrm{EF}=$ Ethyl acetate fraction, $\mathrm{BF}=\mathrm{N}-\mathrm{Butanol}$ fraction, $\mathrm{WF}=$ Water fraction.

$-\quad=$ not present, $\quad+=$ present.

\subsection{Toxicity Studies}

The plant leaves were characterized by a very low degree of toxicity. The acute toxicity $\mathrm{LD}_{50}$ of the CME and fractions of Stachytarphetajamaicensis leaves in mice was found to be above $5000 \mathrm{mg} / \mathrm{kg}$.

\subsection{PRL Content}

To evaluate the effects of both the extract and fractions on PRL secretion, PRL concentration was measured in serum. There was a significant (ANOVA, at least $\mathrm{P}<0.05$ ) increase in serum PRL concentration of the lactating dams treated with the extract and fractions as compared to the controls Figs. $1 \& 2$.

Regarding serum PRL in animals receiving the extract and fractions after treatment with estradiol $\left(\mathrm{E}_{2}\right)$, significantly higher PRL concentrations were observed in the $\mathrm{E}_{2}$-primed animalstreated with extract and fractions as compared to non-primed ones (ANOVA, at least $\mathrm{P}<0.05$ ). Moreover, a significant increase was found for $E_{2}$-primed animals receiving extract and fractions compared to the $E_{2}$-primed control group Figs. 3 $\& 4$. 


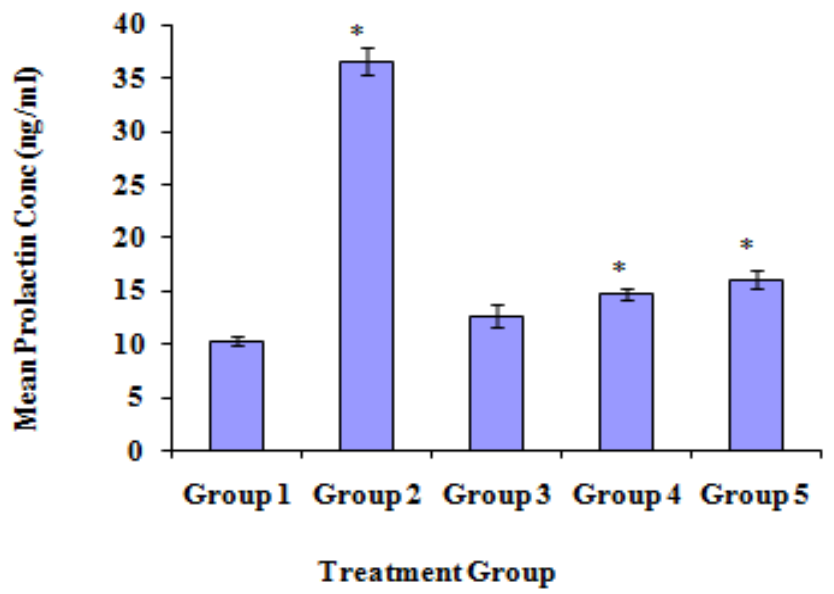

Fig. 1: effect of CME of SJ leaf on the PRL level of treated rats, values are mean \pm SEM, $n=5$, ${ }^{*} p<0.05$, grp $1=$ control (distilled water), grp $2=$ metoclo-treated $(5 \mathrm{mg} / \mathrm{kg}$ b.w.), grp $3=$ extract-treated $(200 \mathrm{mg} / \mathrm{kg}$ b.w.), grp 4 $=$ extract-treated $(400 \mathrm{mg} / \mathrm{kg}$ b.w.), grp $5=$ extract-treated $(800 \mathrm{mg} / \mathrm{kg}$ b.w. $)$.

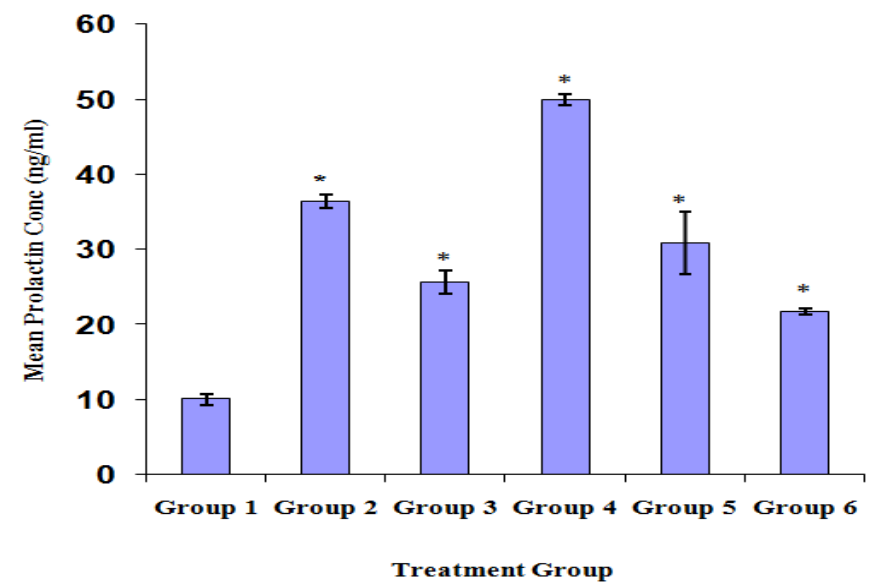

Fig. 2: effect of the fractions of SJ on the prolactin levels of treated rats, values are mean \pm SEM, $n=5$, *p $<0.05$, grp $1=$ control (distilled water), grp $2=$ metoclo-treated $(5 \mathrm{mg} / \mathrm{kg}$ b.w.), grp $3=$ HF-treated $(800$ $\mathrm{mg} / \mathrm{kg}$ b.w.)

Grp 4 = EF-treated ( $800 \mathrm{mg} / \mathrm{kg}$ b.w.), grp 5 = BF-treated $(800 \mathrm{mg} / \mathrm{kg}$ b.w.), grp $6=$ WF-treated $(800 \mathrm{mg} / \mathrm{kg}$ b.w.)

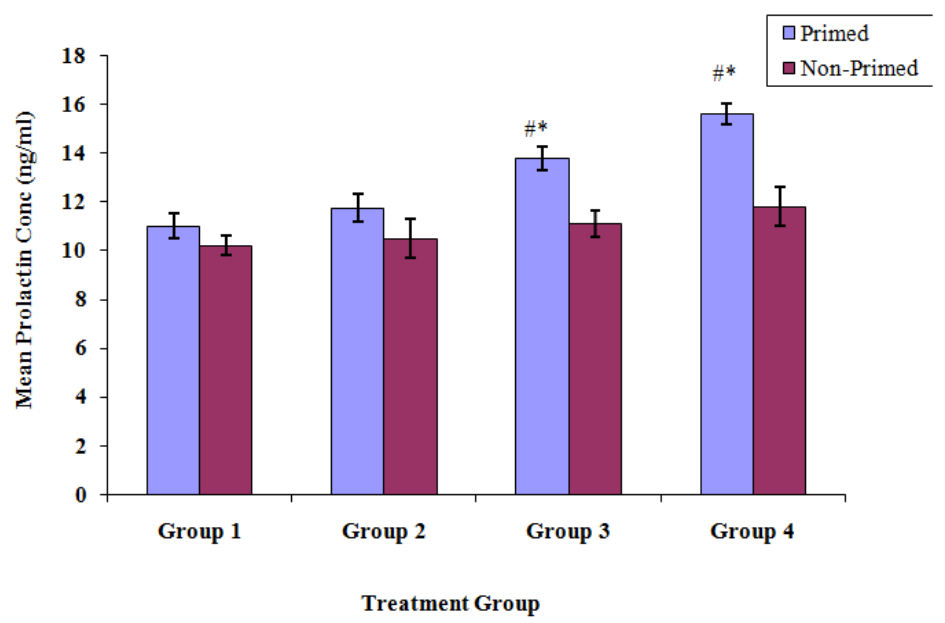

Fig. 3:serum PRL content before and after priming with estradiol $\left(\mathrm{E}_{2}\right)$,values are the mean \pm SEM. *statistically significant compared to the non-primed control, " statistically significant compared to the primed control group (ANOVA, at least $\mathrm{P}<0.05$ ). non-primed: not previously treated with $\mathrm{E}_{2}$. primed: previously treated with $\mathrm{E}_{2}$. group 1: control group receiving $5 \mathrm{ml}$ distilled water (orally, 5days), groups 2, 3 and 4: treated groups receiving 200,400 and $800 \mathrm{mg}$ of plant extract/kg BW (orally, 5days) respectively. 


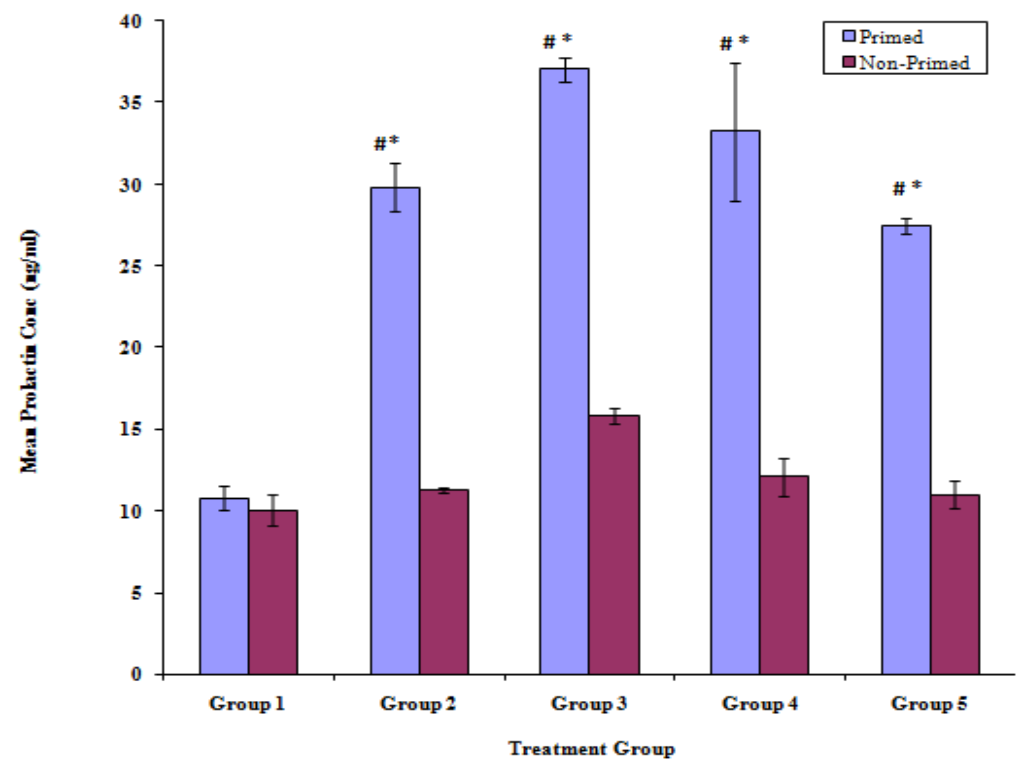

Fig. 4:serum PRL levels before and after priming with estradiol $\left(E_{2}\right)$, values are the mean \pm SEM. *statistically

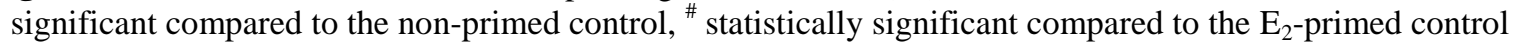
group (ANOVA, at least $\mathrm{P}<0.05$ ). non-primed: not previously treated with estradiol. primed: previously treated with estradiol. group 1: control group receiving $5 \mathrm{ml}$ distilled water (orally, 5days), groups 2, 3, 4 and 5: treated groups receiving n-hexane, ethyl acetate, $\mathrm{n}$-butanol and water $(800 \mathrm{mg} / \mathrm{kg}$ ) BW of fractions (orally, 5days) respectively.

\subsection{Histology of mammary tissue}

To understand the relationship between PRL and mammary growth, the histology of rat mammary gland tissues was studied. The mammary glands of non-primed rats treated with water showed a bare duct system and terminal end buds (TEBs) in a sea of adipose tissue (AT). Although the mammary gland of the $\mathrm{E}_{2-}$ primed animals receiving distilled water consisted of ducts branching into ductules, few budding of rudimentary alveolar was observed. There was evidence of secretions into ducts of the $\mathrm{E}_{2}$-primed groups receiving the extract and fractions when compared to the $\mathrm{E}_{2}$-primed control groups as seen in Figs 5-20.

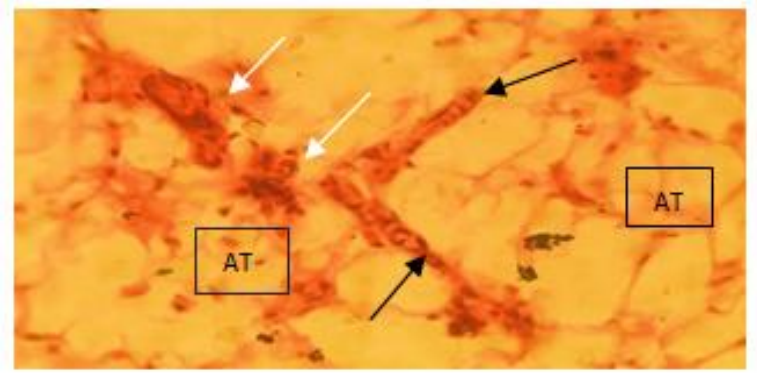

Fig. 5: Histological section of mammary gland from non-primed rat receiving distilled water, showing predominance of bare ducts (white arrow) and terminal end buds (TEB) (black arrow) in a sea of adipose tissue (AT).

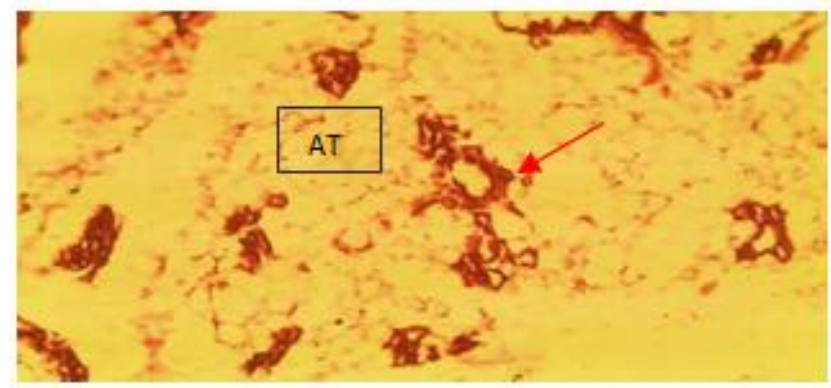

Fig. 6: Histological section of mammary gland from an $\mathrm{E}_{2}$-primed rat receiving distilled water, showing ductular proliferation (red arrow) with few budding of rudimentary alveoli. 


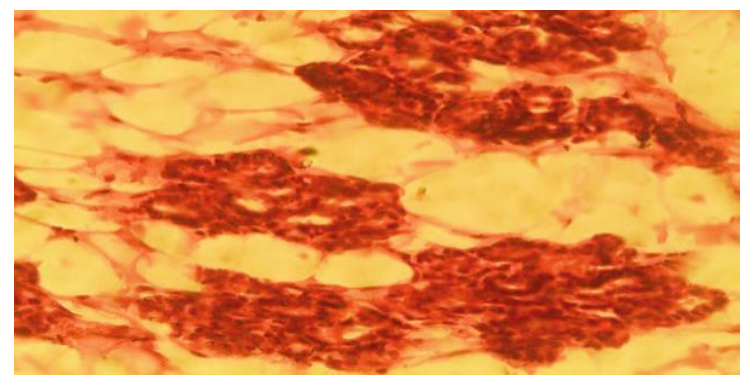

Fig. 7: Histological section of mammary gland from a non-primed rat receiving $200 \mathrm{mg} / \mathrm{kg} \mathrm{BW}$ of plant extract, showing ductular proliferation with moderate budding of rudimentary alveoli.

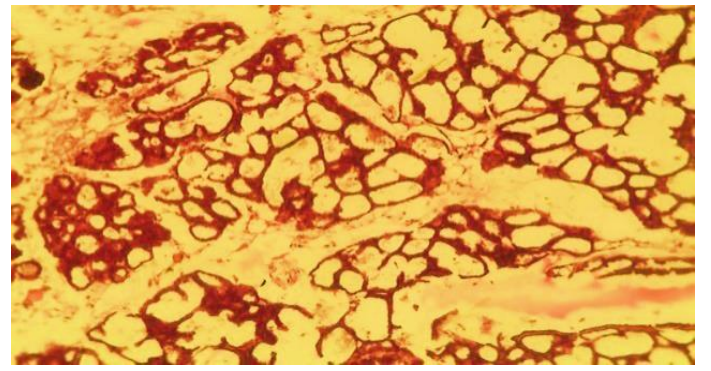

Fig. 8: Histological section of mammary gland from $\mathrm{E}_{2}$-primed rat receiving $200 \mathrm{mg} / \mathrm{kg} \mathrm{BW}$ of plant extract, showing tubuloalveolar differentiation containing proteinaceous materials in the lumen (mild).

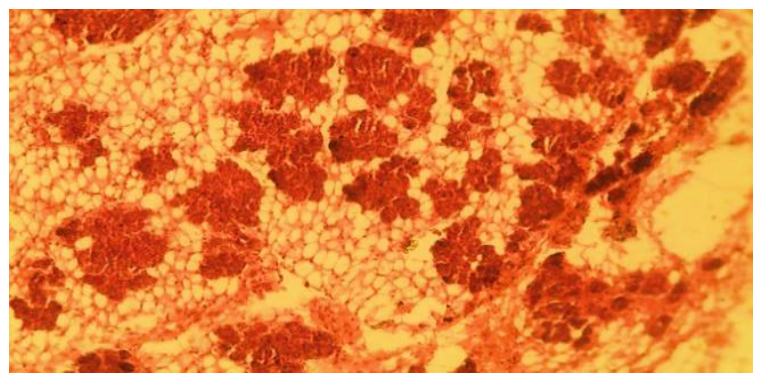

Fig. 9: Histological section of mammary gland from a non-primed rat receiving $400 \mathrm{mg} / \mathrm{kg} \mathrm{BW}$ of plant extract, showing well defined alveolar structure with lipid droplets within the alveoli.

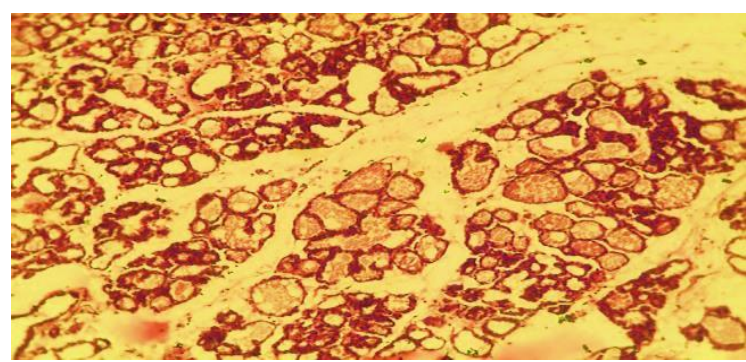

Fig. 10: Histological section of mammary gland from $E_{2}$-primed rat receiving $400 \mathrm{mg} / \mathrm{kg} \mathrm{BW}$ of plant extract, showing tubuloalveolar hyperplasia with proteinaceous materials in the lumen of duct and alveoli (moderate).

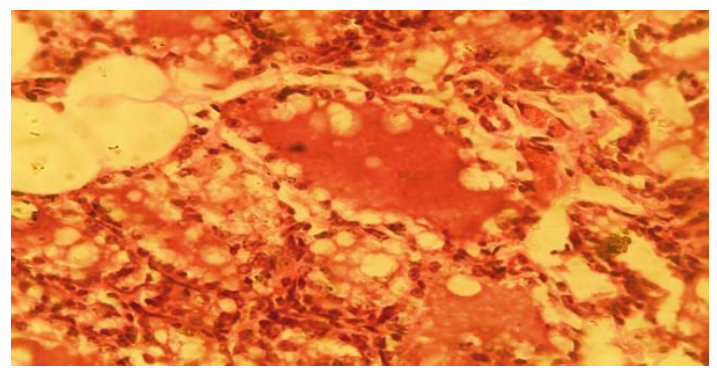

Fig. 11: Histological section of mammary gland from a non-primed rat receiving $800 \mathrm{mg} / \mathrm{kg} \mathrm{BW}$ of plant extract, showing well defined alveolar structure with much lipid droplets in the alveoli. 


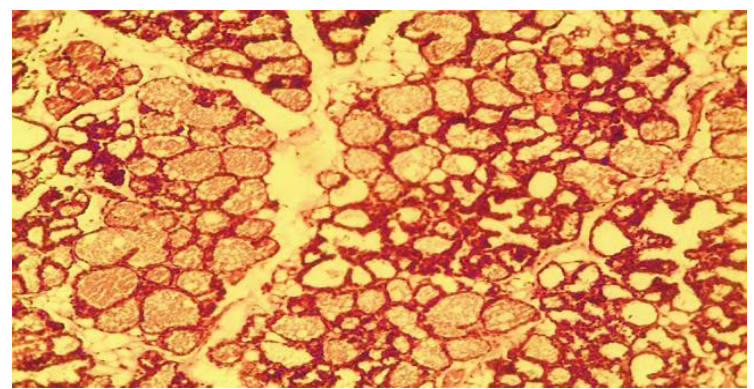

Fig. 12: Histological section of mammary gland from $E_{2}$-primed rat receiving $800 \mathrm{mg} / \mathrm{kg} B W$ of plant extract, showing tubuloalveolar hyperplasia with proteinaceous materials in the lumen of duct and alveoli (high).

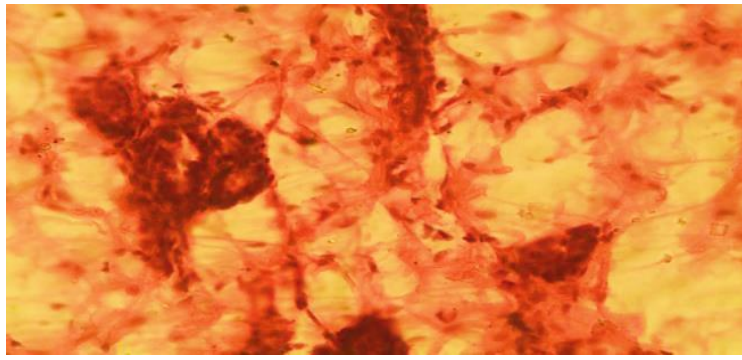

Fig. 13: Histological sections of mammary gland from non-primed rats receiving $n$-hexane fraction in a dose of $800 \mathrm{mg} / \mathrm{kg} \mathrm{BW}$, showing ductular proliferation with moderate budding of rudimentary alveoli.

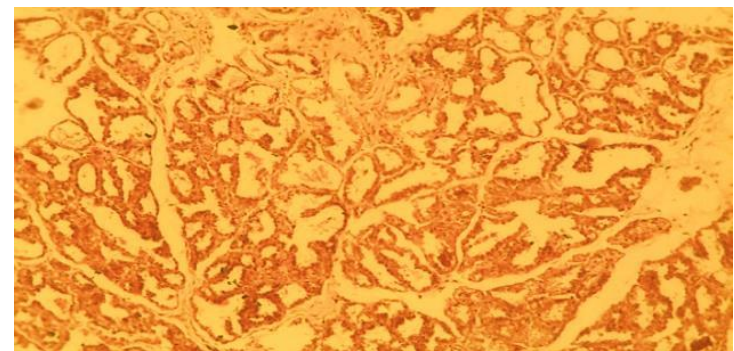

Fig. 14: Histological sections of mammary gland from $E_{2}$-primed ratsreceivingn-hexane fraction in a dose of $800 \mathrm{mg} / \mathrm{kg} \mathrm{BW}$ showing alveolar hyperplasia with dilated alveolar lumens and ducts. The alveoli and ducts contain proteinaceous secretory materials.

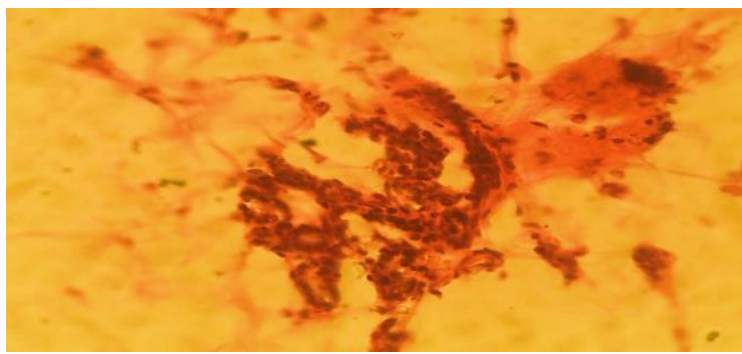

Fig. 15: Histological sections of mammary gland from non-primed rats receiving ethyl acetate fraction in a dose of $800 \mathrm{mg} / \mathrm{kg} \mathrm{BW}$, showing ductular proliferation with moderate budding of rudimentary alveoli.

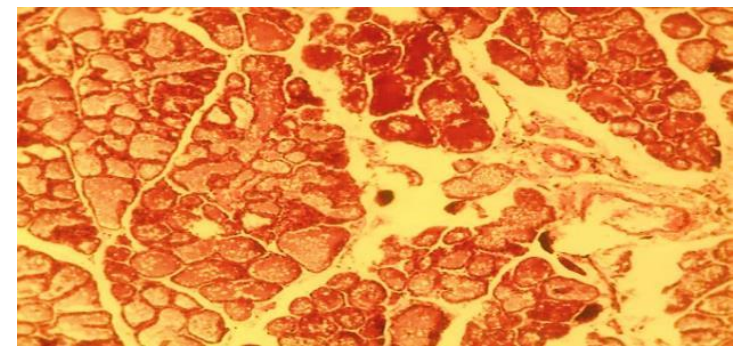

Fig. 16: Histological sections of mammary gland from $\mathrm{E}_{2}$-primed ratsreceivingethyl acetate fraction in a dose of $800 \mathrm{mg} / \mathrm{kg} \mathrm{BW}$, showing alveolar hyperplasia with dilated alveolar lumens and ducts. The alveoli and ducts contain proteinaceous secretory materials. 


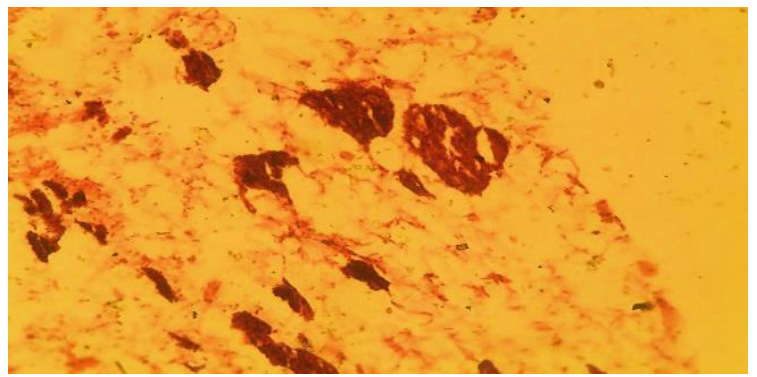

Fig. 17: Histological sections of mammary gland from non-primed rats receiving n-butanol fraction in a dose of $800 \mathrm{mg} / \mathrm{kg} \mathrm{BW}$, showing ductular proliferation with moderate budding of rudimentary alveoli.

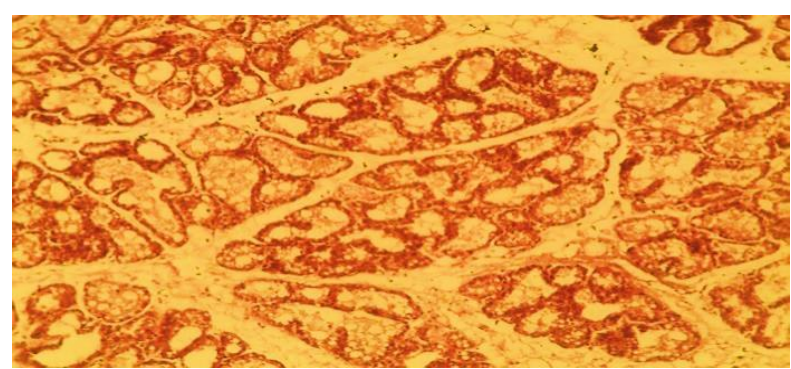

Fig. 18: Histological sections of mammary gland from $\mathrm{E}_{2}$-primed ratsreceivingn-butanol fraction in a dose of $800 \mathrm{mg} / \mathrm{kg} \mathrm{BW}$, showing alveolar hyperplasia with dilated alveolar lumens and ducts. The alveoli and ducts contain proteinaceous secretory materials.

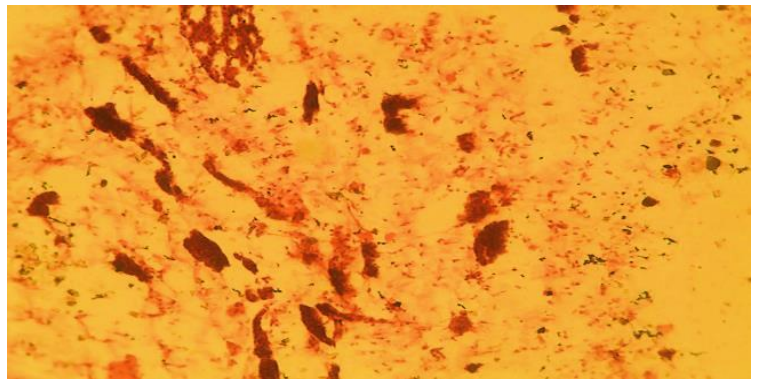

Fig. 19: Histological sections of mammary gland from non-primed rats receiving water fraction in a dose of 800 $\mathrm{mg} / \mathrm{kg} \mathrm{BW}$, showing ductular proliferation with moderate budding of rudimentary alveoli.

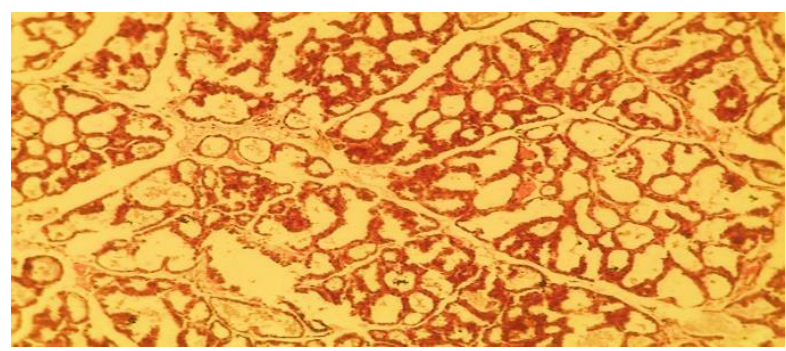

Fig. 20: Histological sections of mammary gland from $\mathrm{E}_{2}$-primed ratsreceivingwater fraction in a dose of 800 $\mathrm{mg} / \mathrm{kg} \mathrm{BW}$, showing alveolar hyperplasia with dilated alveolar lumens and ducts. The alveoli and ducts contain proteinaceous secretory materials.

\section{Discussion}

Milk produced by the mammary gland of humans and other mammals is an essential commoditywhich is the optimal source of nutrition for the newborn infant. The first milk (colostrum) contains relatively high concentrations of sodium chloride and protective substances such as immunoglobulins and lactoferrin while the copious milk secreted contains proteins, lipids, carbohydrates, micronutrients and trace elements required for growth, development and immune protection [26]. The mammary glands can only secrete milk when there is a delicate balance between the reproductive and metabolic hormones however; this must be controlled by feedback inhibitor of lactation (FIL) and the PRL receptor sites [27]. The dramatic change in size, shape and function in association with puberty, pregnancy and lactation which the breast undergoes are critical to successful breastfeeding [28]. 
The lactogenic studies shows that; the CME and fractions of SJ produced an appreciable increase in serum PRL level when compared to the control in a dose-dependent manner and as such exhibited an activity by increasing the serum PRL level in lactating ratsFig. 1. The lactogenic activity displayed by the highest dose of methanol leaf extract $(800 \mathrm{mg} / \mathrm{kg}$ ) when compared with that of metoclopramide (commercial hyperprolactinemia-inducing agent) showed a very wide significant statistical difference in serum PRL level. Interestingly, the ethyl acetate fraction amongst the other fractions of SJ leaf produced a high significant increase in serum PRL level when compared to the control with potency greatly higher than the standard drug metoclopramide and this may be responsible for the lactogenic activity displayed by the CME of the plant; the mechanism of action is still unknown. The extract and fractions showed a progressive but significant increase in lactogenic activity. The activity of the fractions are in the order of Ethyl acetate $>$ n-Butanol $>$ n-Hexane > water $(800 \mathrm{mg} / \mathrm{kg})$ fractions respectively Fig. 2. With respect to the $\mathrm{E}_{2}$-primed animals, the highest serum PRL concentrations were observed in the groups receiving $800 \mathrm{mg} / \mathrm{kg}$ of extract Fig. 3 and the groups receiving $800 \mathrm{mg} / \mathrm{kg}$ of ethyl acetate fraction Fig. 4.

Histologically, the extract and fractions of SJ were able to stimulate mammary gland development and differentiation of the lobulo-alveolar system from the lobular buds with milk secretion within the lumen. The mammary glands of non-primed rats receiving distilled water Fig. 5 showed a predominance of bare duct system and terminal end buds (TEBs) suspended in a sea of adipose tissue (AT). Although the mammary gland of the $\mathrm{E}_{2}$-primed animals receiving distilled water consisted of ductular proliferation (i.e. ducts branching into ductules) Figs. 6, few budding of rudimentary alveoli was observed. In all $E_{2}$-primed animals receiving the extract and fractions, ductular branching with alveolar hyperplasia was observed as well as proteinaceous secretory materials in the alveoli. The largest tubulo-alveolar hyperplasia with proteinaceous materials secreted in the lumen of alveoli and ducts were observed in the $\mathrm{E}_{2}$-primed group receiving $800 \mathrm{mg} / \mathrm{kgof}$ extract Fig. 12 and the $\mathrm{E}_{2}$-primed group receiving $800 \mathrm{mg} / \mathrm{kg}$ of ethyl acetate fraction Fig. 16.

Phytochemical analysis of the extract and fractions revealed the presence of biologically active constituents such as alkaloids, carbohydrates, reducing sugars, flavonoids, steroids, saponins, terpenoids, tannins, glycosides, resins, proteins, oils and acidic compounds. The presence of these phyto-chemical constituents has been reported in SJ [7]. The pharmacological activities of most plant extracts can be traced to these bioactive consitutents. The glycosides and triterpenoids constituents may be responsible for the increase in serum PRL levels and hence contribute to the lactogenic effect of the plant [5].

The plant crude methanol extract and fractions were characterized by a very low degree of toxicity which implies that the leaves of SJ are safe.

\section{Conclusion}

In conclusion, it can be stated that the CME and fractions of SJ effectively increased serum PRL levels as well as stimulated PRL synthesis and release in the rats. The lactogenic activity establishes a rationale for the ethnomedicinal applications and uses of SJ leaves as a galactogogue in lactating women.

The acute toxicity studies of the SJ extract and fractions show that it has a wide therapeutic index which makes it safe for human consumption.

The lactogenic properties of the plant reside in the phytoconstituents.

\section{Acknowledgments}

We would like to appreciate all the authors and the fruitful results they have achieved.

\section{References}

[1]. D.E.Husveth, E.Nyugat-Magyarorszagi, and E.Pannon,Physiological and Reproductional Aspects of Animal Production, Physiology of lactation, 4, 2011, 2-8

[2]. Global Information Hub on Integrated Medicine (Globinmed) (2012)

[3]. E.Gilman,Stachytarphetajamaicensis,BluePorterweed. EDIS Publication \#FPS-559.University of Florida, Gainesvilla.(2011)

[4]. Philippine Pharmacopoeia, University of Philippine printing press, Manila, 3, 2004,pp. B 113- B115

[5]. D.E. Okwu and O.N. Ohenhen, Isolation and Characterization of Steroidal Glycosides and LanostaneTriterpenoid from the leaves of Stachytarphetajamaicensis Linn Vahl. Der Chemical Sinica.1(2), 2010, 6-14.

[6]. S.Susidharan,L.Vega and E.Latha, Antidiarrheal and Antimicrobial activities of Stachytarphetajamaicensis. India Journal of Pharmacology 39,2013245-248.

[7]. M.Idu, E.K. IOmogbai., G.E.Aglumien, F.Amaechina, O.Timothy, and Omonigbo, Preliminary Phytochemistry, Antimicrobial properties and Acute Toxicity of Stachytarphetajamaicensis (L.) Vahl. Leaves. Trends in Medical Research, 2(4),2007, 193-198.

[8]. R. Meena, and R. Pitchai, Evaluation of Antimicrobial Activity and Preliminary Phytochemical studies on Whole plant of Stachytarphetajamaicensis (L)Vahl. International Research Journal of Pharmacy, 2(3),2011, 234-239.

[9]. E.Alvarez, J.M. Leiro, M. RodriguezandF.Orallo, Inhibitory Effects of leaf extracts of Stachytarphetajamaicensis on the respiratory burst of rat macrophages. Phytotherapy Research, 18, 2002, 457-462.

[10]. J.E. Okonkon, E. Etteobong and B.S. Antia, Invivo antimalarial activity of ethanolic leaf extract of Stachytarphetajamaicensis (L.) Vahl.India J.Pharmacol 40 (3), 2008, 111-113.

[11]. C.J.Ikewuchiand C.C. Ikewuchi, Alteration of plasma lipid profiles and Atherogenic indices by Stachytarphetajamaicensis L. (Vahl). Biochemistry,21(2), 2009, 71-77. 
[12]. N.R.N. Jagadish and B. Gopalkrishna, Evaluation of Analgesic activity of different extracts of Stachytarphetaindica .L. (Vahl). Biomed. 3 (3/4),2008229-233.

[13]. P.Chitra,A.Srinivasan, and I.C. Pelapolu, Evaluation of Wound healing activity of hydroalcoholic extract of leaves of Stachytarphetajamaicensisin streptozotocin induced diabetic rats. Der Pharmacia Lettre. 5(2), 2013, 193-200.

[14]. M. McGuffin, C.Hobbs, R.Upton and A.Goldberg,American herbal products association's botanical safety handbook (Boca.Raton, FL, CRC Press, 1997) 107.

[15]. J.C.Kent, D.T. Ramsay and D.Doherty, Response of Breast to different stimulation patterns of an electric breast pump. Hum Lact 19, 2003:179.

[16]. K.R. BrainandT.D.Turner, The Practical Evaluation of Phyto-Pharmaceuticals (Wright-Science Technical: Bristol,1975).

[17]. J.B. Harborne, Phytochemical Methods: A Guide to Modern Technique of Plant Analysis(Chapman and Hall Publishers, London. 1998) $51-59,279$.

[18]. G.E.Trease and W.C. Evans, Trease and Evans Pharmacognosy(W.B. Saunders Ltd., London, 2002).

[19]. D. Lorke, A New Approach to Practice Acute Toxicity Testing Architech of Toxicology (1983). 53: 275-289.

[20]. G.Z.A.Alexandre, M.S.Jr.Jose, L.A.M.Eduardo, J.S.Manuel, M.O.Richardo, A.H.Mauro, R.D.L. Geraldo and C.B. Edmond, Metoclopramide-induced hyperprolactinemia affects mouse endometrial morphology. Gynecol\& obstetric Investigation, 54, 2002, 184-190.

[21]. H.G.Vogel and H.W. Vogel, Drug discovery and evaluation,Pharmacological Assays Springer,1997,645-670.

[22]. D.Dombrwicz,B. Sente, J. Closset andG.Hennen, Dose-dependent effects of human prolactin on immature hypoxrats testis. Endocrinology, 130, 1992695-700.

[23]. E.O. Onuoha, A Practical Guide for the preparation of Histological, Histopathological and Cytological Slides(FEPAM Ventures, Nsukka, 2010).

[24]. I.H. Russo and J. Russo, Mammary neoplasia in long-term rodent studies. Environmental Health Perspectives104, $1996,938-967$.

[25]. P.A. Masso-Welch, K.M. Darcy, N.C. Stangle-Castor and M.M. Ip,A developmental atlas of rat mammary gland histology. Journal of Mammary Gland Biology and Neoplasia5,2000, 165-185

[26]. H.Beerens, O.Romond and C.Neut,Influence of Breastfeeding on the bifid flora of the newborn intestine. Am J ClinNutr.33, 1980, 2434.

[27]. D.B. Cox, R.A. Owens and P.E. Hartmann, Blood and Milk Prolactin and the rate of milk synthesis in Women. Exp Physiol. 81(6), 1996, 1007-20

[28]. M.C.Neville, J. Morton and S.Umemura,Lactogenesis: The transition from pregnancy to lactation. PediatrClin North Am. W.B Saunders Company Published by Elsevier Inc. 48(1), 2001, 35-52. 